\title{
A pre-post test evaluation of the impact of the PELICAN MDT-TME Development Programme on the working lives of colorectal cancer team members
}

\author{
Cath Taylor*1, Joanna M Sippitt², Gary Collins33, Chris McManus4 , Alison Richardson5, Jeremy Dawson6, \\ Michael Richards ${ }^{7}$ and Amanda J Ramirez ${ }^{2}$
}

\begin{abstract}
Background: The PELICAN Multidisciplinary Team Total Mesorectal Excision (MDT-TME) Development Programme aimed to improve clinical outcomes for rectal cancer by educating colorectal cancer teams in precision surgery and related aspects of multidisciplinary care. The Programme reached almost all colorectal cancer teams across England. We took the opportunity to assess the impact of participating in this novel team-based Development Programme on the working lives of colorectal cancer team members.

Methods: The impact of participating in the programme on team members' self-reported job stress, job satisfaction and team performance was assessed in a pre-post course study. 333/568 (59\%) team members, from the 75

multidisciplinary teams who attended the final year of the Programme, completed questionnaires pre-course, and 6-8 weeks post-course.

Results: Across all team members, the main sources of job satisfaction related to working in multidisciplinary teams; whilst feeling overloaded was the main source of job stress. Surgeons and clinical nurse specialists reported higher levels of job satisfaction than team members who do not provide direct patient care, whilst MDT coordinators reported the lowest levels of job satisfaction and job stress. Both job stress and satisfaction decreased after participating in the Programme for all team members. There was a small improvement in team performance.

Conclusions: Participation in the Development Programme had a mixed impact on the working lives of team members in the immediate aftermath of attending. The decrease in team members' job stress may reflect the improved knowledge and skills conferred by the Programme. The decrease in job satisfaction may be the consequence of being unable to apply these skills immediately in clinical practice because of a lack of required infrastructure and/or equipment. In addition, whilst the Programme raised awareness of the challenges of teamworking, a greater focus on tackling these issues may have improved working lives further.
\end{abstract}

\section{Background}

The National PELICAN Multidisciplinary Team Total Mesorectal Excision (MDT-TME) Development Programme was a unique team-based residential training course attended by colorectal multidisciplinary team members across England. The Programme originated as a

* Correspondence: cath.taylor@kcl.ac.uk

1 Florence Nightingale School of Nursing and Midwifery, King's College London, London, SE1 8WA, UK

Full list of author information is available at the end of the article series of workshops funded by Macmillan Cancer Support. It was designed to teach surgeons the technical skills to complete total mesorectal excision (TME) by live demonstration of the surgery using video conferencing facilities, and thereby aimed to improve the quality and usage of TME surgery. The success of these initial workshops led to the NHS commissioning a fully multidisciplinary programme for all members of colorectal multidisciplinary teams[1]. The demonstration of TME remained central to the Development Programme which 
also aimed to provide education about relevant aspects of radiology, histology, oncology and nursing.

We took the opportunity to evaluate the impact of participating in this national team-based course on the working lives of colorectal team members. Underpinning this study was the drive to tackle the high levels of poor mental health reported among UK cancer doctors. In 2002 the estimated prevalence of psychiatric morbidity (GHQ-12 scores 24 ) among UK hospital consultants was $33 \%$ compared with $27 \%$ in 1994 , according to a national cohort study[2,3]. This deterioration in mental health over an eight year period was especially marked in clinical and surgical oncologists and explained by increased job stress without a comparable increase in job satisfaction. Similarly high levels of poor mental health have recently been reported amongst colorectal surgeons and nurse specialists in the UK NHS[4]. On the basis of findings that MDT working may be beneficial to the mental health and working lives of team members[5], we evaluated the impact of participating in this novel MDT-based Development Programme on levels of job stress, levels of job satisfaction and team performance of colorectal cancer team members.

\section{Methods}

\section{Study design and participants}

We conducted a pre-post course evaluation involving all core team members from the 75 teams attending one of the 11 courses in the final year of the programme (September 2005 to October 2006). Core team members included consultant surgeons, oncologists, histopathologists and radiologists, as well as clinical nurse specialists and MDT coordinators.

\section{Procedures}

We ascertained team members through the PELICAN Cancer Foundation, the charity coordinating the Development Programme. Pre-course questionnaires were posted and e-mailed to each core team member approximately three weeks before each course, with a reminder two weeks later. Post-course questionnaires were sent four weeks after each course, with reminders sent six and eight weeks post-course. Consent to participate in the study was assumed by return of a completed questionnaire. Confidentiality was maintained by the allocation of a unique identification number, necessary for matching pre- and post-course responses. Approval for this study was granted by South East Research Ethics Committee and by the Trust Research and Development Department for each multidisciplinary team.

\section{The Development Programme}

In total, 35 courses were held from June 2003 to October 2006. 183 out of 186 colorectal multidisciplinary teams in
England attended (1639 delegates in total). Courses were held on a monthly basis and an average of seven teams attended each course.

Each course lasted two days, over which time team members received education about the management of rectal cancer from national leaders in the field. Central to the course was the opportunity to observe live TME surgery with two-way discussion between operating and lecture theatres using video conferencing facilities. There were also seminars on the latest advances in imaging $[6,7]$, pathology $[8,9]$, pre-operative radio and chemo-radiotherapy[10], supportive care issues including stoma management, and the management of secondary disease. One session was dedicated to the challenges of multidisciplinary team working. This session was unique to each course and chaired by members of the teams in attendance. Team members had the opportunity for social interaction throughout the course by virtue of its residential nature, with overnight accommodation for two nights, together with a course dinner.

\section{Outcomes}

Change in self-reported job stress, job satisfaction, and team performance between pre- and post-course assessment.

\section{Job stress and job satisfaction}

We measured self-reported job stress and job satisfaction using an adapted version of The Hospital Consultants' Job Stress and Satisfaction Questionnaire[11]. The resulting study-specific questionnaire comprised items common to all multidisciplinary team members (46 items related to job stress and 44 items related to job satisfaction) and items relevant only to team members who provide direct patient care: surgeons, oncologists and clinical nurse specialists (10 job stress items and 10 job satisfaction items). See additional file 1 for job stress and satisfaction questionnaire.

Job stress and satisfaction item scores: Each questionnaire item was rated according to the extent it had contributed to an individual's total job stress or total job satisfaction on a scale from 0 (not at all) to 3 (a lot).

Job stress and satisfaction sources scores: Factor analysis was used to explore the grouping of individual stress and satisfaction items. All job satisfaction items aggregated to one of seven main sources of satisfaction. Most job stress items aggregated to one of eight main sources of job stress. Three job stress items did not aggregate to a main source of job stress: 'feeling poorly paid for the job you do'; 'being required to provide routine clinical NHS services outside of normal working hours' and 'disruption to home-life due to on-call work'. Job stress in relation to these items is included in the calculation of total job stress but is not reported individually. Scores for the main sources of job stress and job satisfaction were calculated 
by summing ratings given to the individual items that aggregated to each source and were standardised (on a scale of 0-100). For each score presented, the higher the score the higher the level of job stress or job satisfaction.

Total job stress and satisfaction scores: Total job stress and job satisfaction scores were calculated by summing ratings given to all job stress and job satisfaction items respectively. Scores were standardised (on a scale of 0100) to aid comparison between team members who did and did not provide direct patient care.

\section{Team performance}

Key aspects of team performance were measured the Aston Team Performance Inventory[12] (ATPI). Each team member rated 33 statements on a five-point scale from 'Strongly Disagree' to 'Strongly Agree'. Total team performance scores were calculated by aggregating responses to all 33 statements. Individual statements also aggregated to one of six domains of team-working (table 1). Scores were standardised to enable comparison across domains. The ATPI is designed for use as a team-level measure and therefore for each team in the study, the response from individual members was averaged to give team-based total and domain scores.

Pre-course expectations of the Development Programme and reported adequacy of skills training for effective

\section{multidisciplinary team working}

At the pre-course assessment, team members completed an open-ended question: 'What are you hoping to gain from the PELICAN MDT-TME Development Programme?' At that assessment team members also reported whether they felt adequately trained in communication skills, teamworking skills, handling complaints from patients and relatives, and team leadership.

\section{Statistical Methods}

We assessed the impact of participation in the Development Programme on job stress, job satisfaction and team performance by analysing responses from team members who responded to both pre- and post-course questionnaires $(n=333)$. Analysis of team performance excluded one team as only one member responded to both preand post-course questionnaires.

We used repeated measures ANOVA to assess the impact of participation in the Development Programme on team members' job satisfaction and job stress (total levels and individual sources) and team performance. Due to the exploratory nature of this study no adjustment was made for multiple testing. Analysis was conducted using SPSS v.15 and R v.2.6.0.

Responses to the pre-course open-ended question about team members' expectations of the Development Programme were read and main themes described independently by four members of the research team. Once themes were agreed, one member of the research team coded each response according to the agreed framework.

\section{Results}

Participant flow

Between September 2005 and October 2006, 568 team members from 75 teams participated in the Development Programme at one of 11 courses. 464/568 (82\%) team members responded to the pre-course questionnaire and $367 / 568$ (65\%) to the post-course questionnaire. A total of 333 team members (59\%) responded to both pre- and post- course questionnaires. The average number of respondents per team was 7 (range 1 to 10).

\section{Characteristics of team members}

Team members who completed both pre- and postcourse questionnaires and those who were lost to followup had very similar baseline characteristics, including having similar levels of total job stress and job satisfaction (table 2). 104 team members participated in the Development Programme but did not complete either pre- or post- course questionnaires. Of these, 67 (65\%) were male; 46 (45\%) were surgeons and $21(20 \%)$ were clinical nurses specialists.

Over half of the team members who participated in the evaluation of the Programme were clinical nurse specialists or surgeons. Overall, the proportions of male and female team members were similar, but over $90 \%$ of MDT coordinators and clinical nurse specialists were female, whereas $90 \%$ of surgeons and $79 \%$ of radiologists were male.

Most surgeons and nurses were core members of only one multidisciplinary team, but the majority of oncologists, radiologists and histopathologists were core members of between two and four teams. Five percent of team members were core members of between five and nine different teams; over half of these were oncologists.

\section{Job stress and job satisfaction among colorectal cancer teams members at the pre-course assessment}

Among all team members 'feeling overloaded with work and impact on home life' was the most frequently reported source of job stress. 'Dealing with angry or blaming patients/relatives' was associated with similarly high levels of job stress amongst team members who provide direct patient care (table 1). Across the professional groups surgeons reported the highest total job stress although only significantly higher than MDT coordinators. MDT coordinators reported the lowest job stress; significantly lower than all other professional groups $\left(\mathrm{F}_{5,327}=4.9, \mathrm{p}<0.001\right)$. This pattern of differences in levels of total job stress across the professional groups was repeated for each of the individual sources of job stress (table 3).

The highest levels of job satisfaction were reported by team members who provide direct patient care and related to 'having good relationships with patients' and 'providing quality care to patients'. Across all team mem- 
Table 1: Impact of participation in the MDT-TME Development Programme on job stress, job satisfaction and team performance

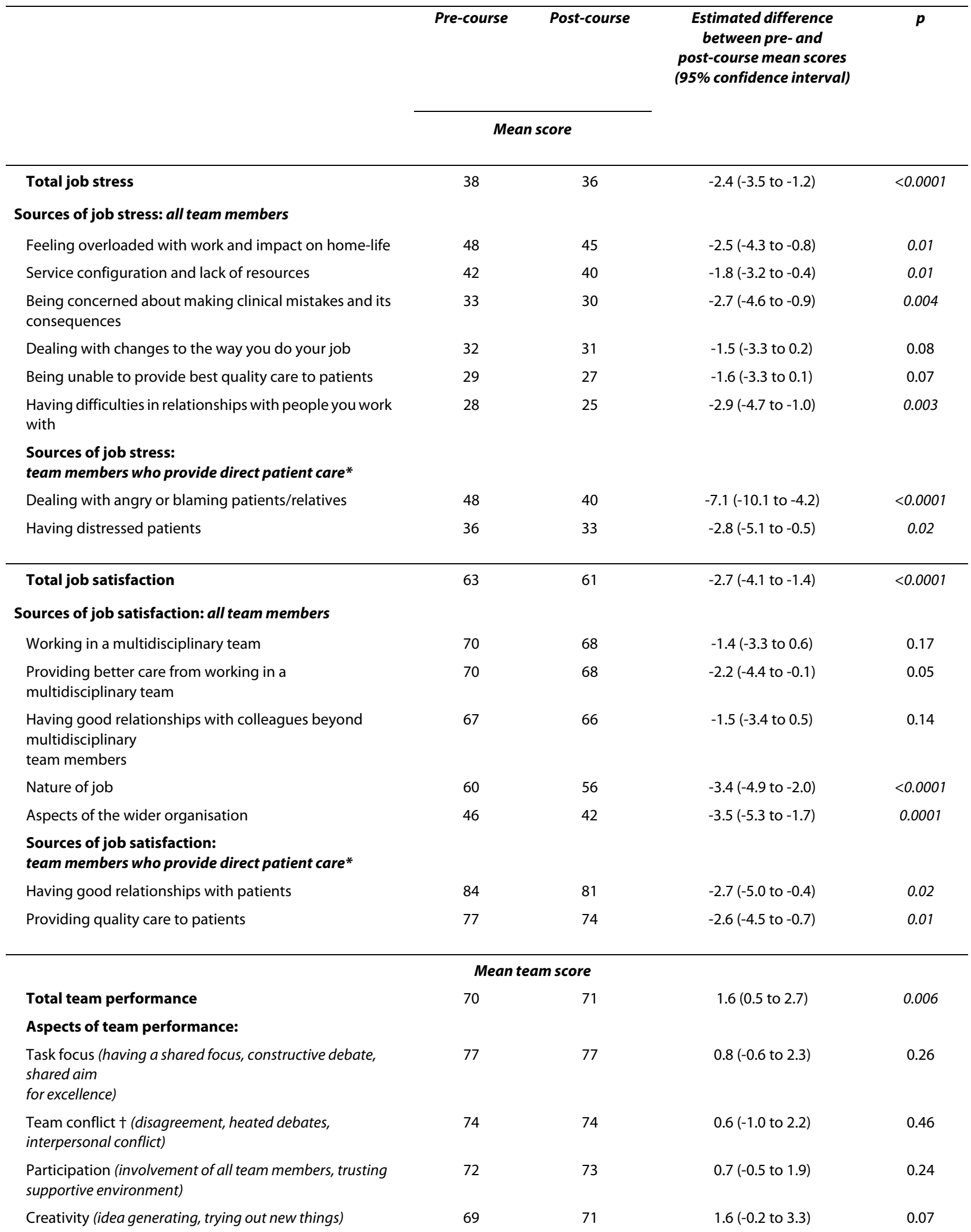


Table 1: Impact of participation in the MDT-TME Development Programme on job stress, job satisfaction and team performance (Continued)

\begin{tabular}{llll}
\hline $\begin{array}{l}\text { Managing (how well the team leader organises and } \\
\text { coordinates team, } \\
\text { monitors quality, progress and provides feedback) }\end{array}$ & 68 & 69 & $0.8(-0.7$ to 2.4$)$ \\
$\begin{array}{l}\text { Reflexivity (reviewing team's objectives, discussing how } \\
\text { team is working) }\end{array}$ & 59 & 61 & $2.0(0.3$ to 3.7$)$ \\
\hline
\end{tabular}

* completed by surgeons, oncologists and clinical nurse specialists only; $\uparrow$ scores reversed (higher score $=$ less conflict)

bers 'working in a multidisciplinary team' and 'providing better care from working in a multidisciplinary team' were the predominant sources of job satisfaction (table 1). Surgeons and clinical nurse specialists reported the highest job satisfaction; significantly higher than all other team members except oncologists. MDT coordinators reported the lowest satisfaction; significantly lower than all other team members $\left(\mathrm{F}_{5,326}=16.5 ; \mathrm{p}<0.001\right)$. As with job stress, the pattern of job satisfaction levels by professional group for the individual sources of job satisfaction was similar to the pattern for total job satisfaction (table $3)$.

Impact of the Development Programme on job stress, job satisfaction and team performance

Across all team members, levels of total job stress decreased after participation in the Development Programme (table 1). Levels of job stress decreased in six out of the eight individual sources (table 1). The decrease in total job stress was similar across all professional groups, as was the decrease in relation to seven of the eight individual source of job stress (table 3).

Levels of total job satisfaction also decreased after participation in the Development Programme (table 1). Levels of job satisfaction decreased in four out of the seven individual sources (table 1). The decrease in total job satisfaction and each individual source of job satisfaction was similar across each professional group (table 3).

There was a small increase in team performance scores after participation in the Development Programme. This was mostly accounted for by an increase in one aspect of team performance: the extent to which the team reflected on their objectives and the way their team was working (reflexivity; table 1).

Team members' expectations regarding the Development Programme

278 (83\%) team members responded to the pre-course question about their expectations of the Development Programme. The majority $(240 / 278 ; 87 \%)$ gave a response that aggregated to one of two main themes:

- To assess or improve their team working $(n=206$, $74 \%$ ): to assess their team working in relation to others; or improve their team working (e.g. improve relationships within the team, increase efficiency, manage conflict or gain a better understanding of other team members' roles):

'Reassurance we are working together effectively and that our discussions are broadly in line with national thinking'

'How to make the MDT more effective, efficient and professional with more input from all members'

'An increased awareness of the responsibilities of the other disciplines'

'I hope that as a result of the Programme our team may become more cohesive and be more functional, respectful and supportive'

- To improve their knowledge ( $\mathrm{n}=80,29 \%)$ : to be educated about best practice, latest advancements, and training or learning specific to their role.

'To improve my knowledge and skills in colorectal cancer management'

'To improve my skills and understanding of MRI staging of rectal cancer and to improve the quality of the imaging'

\section{Adequacy of skills training for effective multidisciplinary teamworking}

Prior to attending the Development Programme, three quarters of team members felt adequately trained in communication skills but this varied from $86 \%$ of nurses to only just over half of radiologists (table 4). Two-thirds of team members felt adequately trained in teamworking skills. Less than $40 \%$ of respondents felt adequately trained in dealing with complaints, with particularly low proportions of radiologists (19\%) and MDT coordinators (16\%) feeling adequately trained. Less than a third of team members felt adequately trained in team leadership.

\section{Discussion}

For the colorectal team members we evaluated, participating in the MDT-TME Development Programme was associated with a decrease in average levels of job stress and job satisfaction six to eight weeks post-course. Team members also reported a marginal improvement in team performance. The magnitude of the decrease in team members' levels of job stress and job satisfaction was similar to the increase in job stress reported by UK hospital consultants between 1994 and 2002 using the same mea- 
Table 2: Demographic and professional characteristics of colorectal team members

\begin{tabular}{|c|c|c|}
\hline & $\begin{array}{l}\text { Team members who completed pre- and } \\
\text { post- course questionnaires } \\
n=333(\%)\end{array}$ & $\begin{array}{l}\text { Team members who completed pre-course } \\
\text { questionnaire only } \\
n=131(\%)\end{array}$ \\
\hline \multicolumn{3}{|l|}{ AGE GROUP } \\
\hline 25 and under & $2(1)$ & $1(1)$ \\
\hline $26-35$ years & $35(11)$ & $14(11)$ \\
\hline $36-45$ years & $159(48)$ & $48(38)$ \\
\hline $46-55$ years & $102(31)$ & $48(38)$ \\
\hline Over 55 years & $33(10)$ & $14(11)$ \\
\hline Missing & 2 & 6 \\
\hline \multicolumn{3}{|l|}{ GENDER } \\
\hline Male & $176(53)$ & $74(57)$ \\
\hline Female & $157(47)$ & $57(44)$ \\
\hline \multicolumn{3}{|l|}{ MARITAL STATUS } \\
\hline Single & $28(8)$ & $11(9)$ \\
\hline Married/cohabiting & $285(86)$ & $104(83)$ \\
\hline Separated/divorced/widowed & $18(5)$ & $10(8)$ \\
\hline Missing & 2 & 6 \\
\hline \multicolumn{3}{|l|}{ PROFESSIONAL GROUP } \\
\hline Surgeons & $94(28)$ & $45(34)$ \\
\hline Oncologists & $35(11)$ & $15(12)$ \\
\hline Radiologists & $57(17)$ & $15(12)$ \\
\hline Histopathologists & $27(8)$ & $14(11)$ \\
\hline Clinical nurse specialists & $95(29)$ & $32(24)$ \\
\hline \multirow[t]{2}{*}{ MDT coordinators } & $25(8)$ & $10(8)$ \\
\hline & \multicolumn{2}{|c|}{ Mean score } \\
\hline $\begin{array}{l}\text { TOTAL JOB STRESS } \\
\text { (pre-course) }\end{array}$ & 38 & 39 \\
\hline $\begin{array}{l}\text { TOTAL JOB SATISFACTION } \\
\text { (pre-course) }\end{array}$ & 63 & 63 \\
\hline
\end{tabular}

sures[3]. The increase in job stress explained a five percent increase in prevalence of estimated psychiatric morbidity among UK hospital consultants over that time period (from $27 \%$ to $32 \%$ with GHQ-12 scores $\geq 4$ ). This suggests that the impact of the Development Programme on the well-being of colorectal team members is meaningful. The improvement in team performance scores was mainly explained by a change in the extent to which teams reflected on their teamworking. This has face validity given the nature of the Programme. Its importance is however difficult to interpret as the Aston Team Performance Inventory has yet to be validated against measures of the effectiveness of multidisciplinary teams including the mental health of team members.

These findings are challenging to interpret. The decrease in team members' job stress may reflect the improved knowledge and skills that the Development Programme conferred. The decrease in job satisfaction may be the consequence of being unable to apply these newly acquired skills in the immediate aftermath of the Development Programme because of a lack of required infrastructure and/or equipment. Early reports suggest that attendance at the Development Programme has improved clinical practice, including increased usage of 
Table 3: Impact of participation in the MDT-TME Development Programme on job stress and job satisfaction by professional group

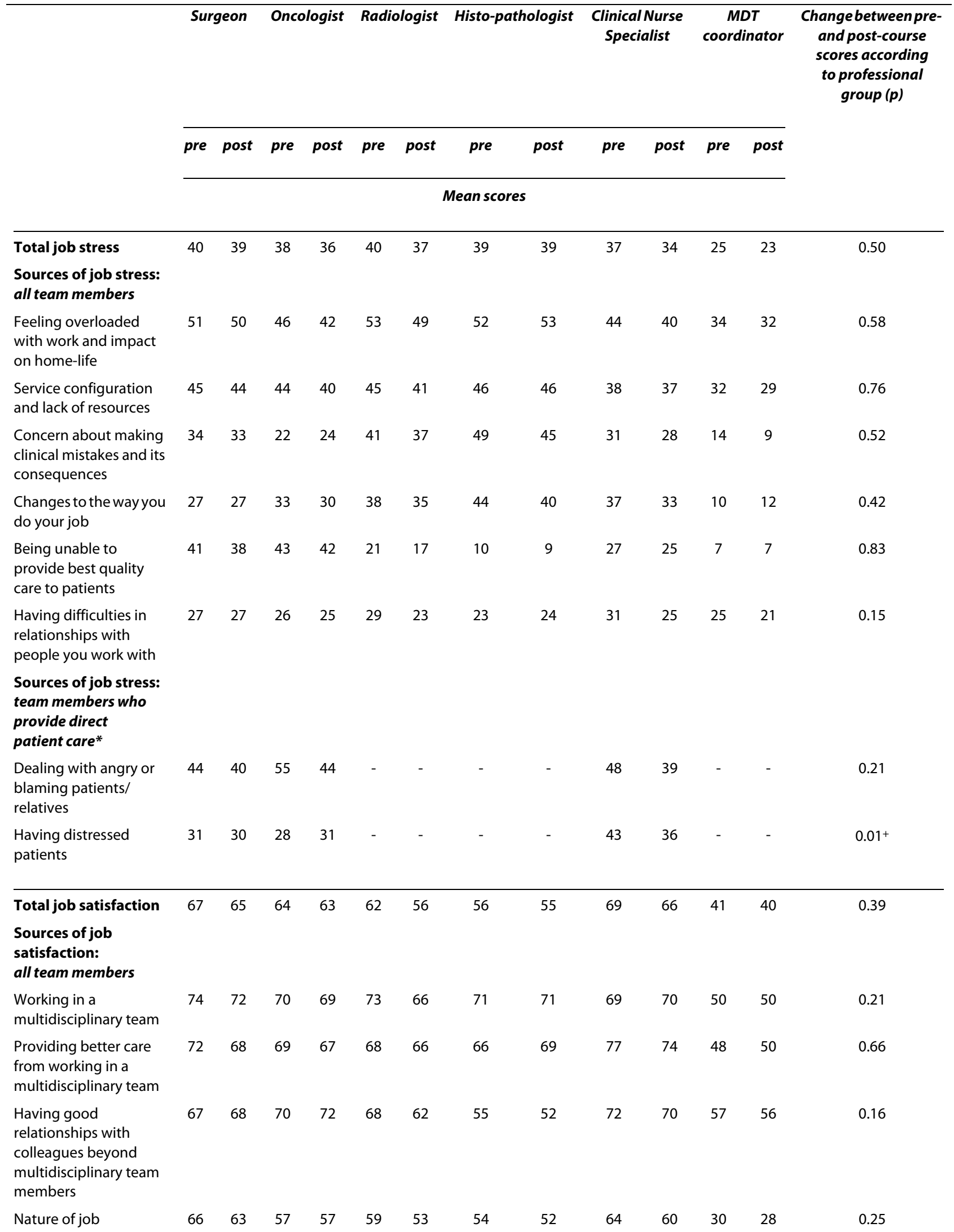


Table 3: Impact of participation in the MDT-TME Development Programme on job stress and job satisfaction by professional group (Continued)

\begin{tabular}{|c|c|c|c|c|c|c|c|c|c|c|c|c|c|}
\hline $\begin{array}{l}\text { Aspects of the wider } \\
\text { organisation }\end{array}$ & 46 & 44 & 46 & 44 & 45 & 40 & 42 & 40 & 50 & 45 & 37 & 36 & 0.57 \\
\hline $\begin{array}{l}\text { Sources of job } \\
\text { satisfaction: } \\
\text { team members who } \\
\text { provide direct } \\
\text { patient care* }\end{array}$ & & & & & & & & & & & & & \\
\hline $\begin{array}{l}\text { Having good } \\
\text { relationships with } \\
\text { patients }\end{array}$ & 83 & 80 & 82 & 79 & - & - & - & - & 86 & 84 & - & - & 0.97 \\
\hline $\begin{array}{l}\text { Providing quality care } \\
\text { to patients }\end{array}$ & 74 & 72 & 72 & 70 & - & - & - & - & 83 & 79 & - & - & 0.50 \\
\hline
\end{tabular}

MRI preoperatively (Brown, personal communication, 27.05.10); improved quality of reporting for radiology and increased lymph-node harvest (Yorkshire Audit Data, Quirke, personal communication, 08.06.10). An internal evaluation of the impact of the Development Programme on clinical practice 6-12 months after participation[13] also reports improved usage and reporting of MRI subsequent to attendance, as well as the adoption of new network-wide policies and protocols. However, some teams also reported being unable to implement some of the recommendations of the Programme due to workforce shortages. These included dual consultant operating for difficult cases and not having an MDT coordinator or clinical nurse specialist as part of the team.

Across all team members the main sources of job satisfaction related to working in a multidisciplinary team and providing better patient care as a result of multidisciplinary teamworking. This finding is consistent with findings from a national survey completed by over 2000 MDT members in England, of whom 90\% agreed that MDTworking is beneficial to the mental health and wellbeing of team members, and $81 \%$ agreed that being an MDT member improves job satisfaction[14]. The perception that teamworking improves patient care fits with the emerging evidence that multidisciplinary teams are beneficial in terms of disease management and clinical outcomes[15].

The levels and nature of job stress and satisfaction among hospital consultants has already been well described [2,3] but this study provided a unique opportunity for comparison across all core colorectal members of multidisciplinary teams. We found that clinical nurse specialists reported similarly high levels of job stress as their medical colleagues. These high levels for nurses may reflect a lack of clarity about the content and boundaries of their job leading to excessive expectations from others[16-19]. They also reported high job satisfaction which is likely to be derived from spending most of their working time delivering direct patient care[16], as well as the positive impact on their professional status and esteem of being recognised as a core member of the multidisciplinary team in recent cancer policy. Having professional status and esteem has been shown to be a key source of satisfaction for hospital consultants[2,3]. MDT coordina-

Table 4: Adequacy of skills training for effective multidisciplinary teamworking

\begin{tabular}{|c|c|c|c|c|}
\hline Professional Group & $\begin{array}{c}\text { Communication skills } \\
n(\%)\end{array}$ & $\begin{array}{c}\text { Teamworking } \\
n(\%)\end{array}$ & $\begin{array}{c}\text { Handling complaints } \\
n(\%)\end{array}$ & $\begin{array}{c}\text { Team leadership } \\
\mathbf{n}(\%)\end{array}$ \\
\hline Surgeons & $76(81)$ & $64(68)$ & $49(52)$ & $43(46)$ \\
\hline Oncologists & $27(77)$ & $18(51)$ & $15(43)$ & $13(37)$ \\
\hline Radiologists & $31(54)$ & $33(58)$ & $11(19)$ & $11(19)$ \\
\hline Histopathologists & $18(67)$ & $17(63)$ & $9(33)$ & $6(22)$ \\
\hline Clinical nurse specialists & $82(86)$ & $68(72)$ & $42(44)$ & $23(24)$ \\
\hline MDT coordinators & $18(72)$ & $15(60)$ & $4(16)$ & $2(8)$ \\
\hline TOTAL $(n=333)$ & $252(76)$ & $215(65)$ & $133(39)$ & $98(29)$ \\
\hline
\end{tabular}


tors, who prepare and organise the multidisciplinary team meetings, have a relatively new and rapidly expanding role[20]. The importance of MDT coordinators for effective MDT working has been acknowledged[20,21]. However, their low job stress and low job satisfaction suggests the need to standardise and professionalise their work[22].

Strengths of this study include the response from almost $60 \%$ of team members from a third of all colorectal cancer teams in England to both pre- and post-course questionnaires. We received completed questionnaires from $82 \%$ of delegates pre-course and found no difference in total job stress and satisfaction scores between those who responded to follow-up and those who did not. We also used well validated job stress and satisfaction measures, designed specifically for cancer health professionals[11]. The Development Programme reached almost every colorectal cancer team in England and thus we chose a pre-post evaluation design as a randomised controlled trial was not possible. Our evaluation focused on only the final year of the programme, which was for pragmatic reasons. The relatively short timeframe of followup may have impacted on the results. Benefits may have dissipated in the long-term. Alternatively, gains in job satisfaction may have been reported in the longer term, once the challenges of instigating the necessary service changes had been overcome.

The Development Programme was not intended to provide training in teamworking. Nevertheless, a large proportion of team members attended the course with expectations that it would do so. This study highlights significant shortfalls in the training that multidisciplinary team members reported they had received in the skills that are key to effective teamworking, namely in communication, teamworking, handling complaints and leadership. Amongst these skills, effective leadership is arguably the most critical to the success of teamworking, supported by the recommendation for standardised leadership training by Lord Darzi[23]. To address the outstanding need for teamwork training identified by colorectal team members, the methods used to improve communication skills in cancer health professionals[24] could be integrated into courses such as the Development Programme.

\section{Conclusions}

Participation in the Development Programme had a mixed impact on the working lives of team members in the immediate aftermath of attending. Although challenging to interpret, the decrease in team members' job stress may reflect the improved knowledge and skills conferred to many participants by the Programme. The decrease in job satisfaction may be the consequence of being unable to apply these skills immediately in clinical practice because of a lack of required infrastructure and/ or equipment. In addition, whilst the Programme raised awareness of the challenges of teamworking, a greater focus on tackling these issues in combination with enhancing clinical skills and knowledge may go further to improve the working lives of cancer multidisciplinary team members.

\section{Additional material}

Additional file 1 Adapted version of the hospital consultants' job

stress and job satisfaction questionnaire. The questionnaire used to

assess cancer team members' job stress and job satisfaction.

\section{Abbreviations}

ANOVA: Analysis of variance; ATPI: Aston Team Performance Inventory; MDT: Multidisciplinary team; NHS: National Health Service; TME: Total Mesorectal Excision.

\section{Competing interests}

The authors declare that they have no competing interests.

\section{Authors' contributions}

All named authors have agreed to the submission of this manuscript and participated in this study to a sufficient extent to be named as authors. AJR and MR conceived the idea for the study; CT was the study lead and wrote the first draft of the paper; JS was the study coordinator; GC provided statistical support; CMc, AR and JD advised on aspects of study design and interpretation of findings. All authors participated in the critical revision of the article and have read and approved the final manuscript.

\section{Acknowledgements}

This study was funded by Cancer Research UK. We thank all of the colorectal cancer team members who participated in this study; Dr Gina Brown, Mrs Celia Ingham Clark, Maggie Vance, Theresa Porrett, Jill Dean and Sue Bates for their support in encouraging participation; the PELICAN Cancer Foundation (Juliet Crawley, Julia Jessop; Chris Beagley and all the faculty) for facilitating the evaluation; Sinead Drew, Jenny Harris, Emma Teasdale and Chris Papadopoulos for assisting with data collection and analysis.

\section{Author Details}

1Florence Nightingale School of Nursing and Midwifery, King's College London, London, SE1 8WA, UK, 2Promoting Early Presentation Group, Institute of Psychiatry, King's College London, Adamson Centre, St Thomas' Hospital, London, SE1 7EH, UK, ${ }^{3}$ Centre for Statistics in Medicine, Wolfson College Annexe, University of Oxford, Oxford, OX2 6UD, UK, 4Department of Psychology, University College London, Gower Street, London, WC1E 6BT, UK, ${ }^{5}$ School of Health Sciences, University of Southampton and Southampton University Hospital Trust, Southampton, SO16 6YD, UK, 6Work \& Organisational Psychology Group, Aston Business School, Aston University Aston Triangle, Birmingham, B4 7ET, UK and 'National Cancer Action Team, St Thomas' Hospital, London, SE1 7EH, UK

Received: 23 November 2009 Accepted: 29 June 2010 Published: 29 June 2010

\section{References}

1. Jessop J, Beagley C, Heald RJ: The Pelican Cancer Foundation and the English National MDT-TME Development Programme. Colorectal Disease 2006, 8:1-2.

2. Ramirez AJ, Graham J, Richards MA, Cull A, Gregory WM: Mental health of hospital consultants: The effects of stress and satisfaction at work. Lancet 1996, 347:724-728.

3. Taylor C, Graham J, Potts HWW, Richards MA, Ramirez AJ: Changes in mental health of UK hospital consultants since the mid-1990s. Lancet 2005, 366:742-744. 
4. Sharma A, Sharp DM, Walker LG, Monson JRT: Stress and burnout among colorectal surgeons and colorectal nurse specialists working in the National Health Service. Colorectal Disease 2007, 10:397-406.

5. Haward B, Amir Z, Borrill C, Dawson J, Scully J, West MA, Sainsbury R: Breast Cancer Teams: The impact of constitution, new cancer workload, and methods of operation on their effectiveness. British Journal of Cancer 2003, 89:15-22.

6. Burton S, Brown G, Daniels IR, Norman AR, Mason B, Cunningham D: MRI directed multidisciplinary team preoperative treatment strategy: the way to eliminate positive circumferential margins? British Journal of Cancer 2006, 94:351-357.

7. MERCURY Study Group: Diagnostic accuracy of preoperative magnetic resonance imaging in predicting curative resection of rectal cancer: prospective observational study. BMJ 2006, 333:779-784.

8. Quirke P: Training and quality assurance for rectal cancer: 20 years of data is enough. Lancet Oncology 2003, 4:695-702.

9. West NP, Morris EJ, Rotimi O, Cairns A, Finan PJ, Quirke P: Pathology grading of colon cancer surgical resection and its association with survival: a retrospective observational study. Lancet Oncology 2008, 9:857-865.

10. Glynne-Jones R, Sebag-Montefiore D, Samuel L, Falk S, Maughan T, McDonald A: Socrates phase II study results: capecitabine combined with oxaliplatin and preoperative radiation in patients with locally advanced rectal cancer. J CLIN ONCOL 2005, 23:3527.

11. Teasdale E, Drew S, Taylor C, Ramirez AJ: Hospital Consultants' Job Stress and Satisfaction Questionnaire. 2008 [http://www.iop.kcl.ac.uk/iopweb/ blob/downloads/locator// 370 HCJSSO Manual.pdf]. Cancer Research UK London Psychosocial Group

12. West MA, Markiewicz L, Dawson FC: Aston Team Performance Inventory. London, ASE; 2005.

13. Jessop J: National MDT-TME Development Programme: changes to clinical practice. 2007.

14. admin@pelicancancer.org

15. Taylor C, Ramirez AJ: Multidisciplinary team members' views about MDT working: results from a survey commissioned by the National Cancer Action Team. 2009

16. Taylor C, Munro AJ, Glynne-Jones R, Griffith C, Trevatt P, Richards M, Ramirez AJ: Multidisciplinary team working in cancer: what is the evidence? BMJ 2010, 340:C951.

17. Royal College of Nursing: Maxi Nurses. Advanced and Specialist Nursing Roles: Results from a survey of RCN members in advanced and specialist nursing roles Royal College of Nursing, London; 2005.

18. Willard C, Luker K: Working with the team: strategies employed by hospital cancer nurse specialists to implement their role. J CLIN NURS 2007, 16:716-724.

19. Lloyd-Jones M: Role development and effective practice in specialist and advanced practice roles in acute hospital settings: systematic review and meta-synthesis. J ADV NURS 2005, 49:191-209.

20. Trevatt P, Petit J, Leary A: Mapping the English cancer clinical nurse specialist workforce. Cancer Nursing Practice 2008, 7:33-38.

21. Kelly M, Lloyd T, Marshall D, Garcea C, Sutton C, Beach M: A snapshot of MDT working and patient mapping in the UK colorectal cancer centres in 2002. Colorectal Disease 2003, 5:577-581.

22. National Cancer Action Team: The characteristics of an effective multidisciplinary team. National Cancer Action Team, London; 2010

23. Soukop M, Robinson A, Soukop D, Ingham-Clark CL, Kelly MJ: Results of a survey of the role of multidisciplinary team coordinators for colorectal cancer in England and Wales. Colorectal Disease 2007, 9:146-150

24. Department of Health: High quality care for all: NHS next stage review final report. Department of Health, London; 2008.

25. Fallowfield L, Jenkins V, Farewell V, Saul J, Duffy A, Eves R: Efficacy of a Cancer Research UK communication skills training model for oncologists: a randomised controlled trial. The Lancet 2002, 359:650-56.

Pre-publication history

The pre-publication history for this paper can be accessed here: http://www.biomedcentral.com/1472-6963/10/187/prepub

doi: $10.1186 / 1472-6963-10-187$

Cite this article as: Taylor et al., A pre-post test evaluation of the impact of the PELICAN MDT-TME Development Programme on the working lives of colorectal cancer team members BMC Health Services Research 2010, 10:187

Submit your next manuscript to BioMed Centra and take full advantage of:

- Convenient online submission

- Thorough peer review

- No space constraints or color figure charges

- Immediate publication on acceptance

- Inclusion in PubMed, CAS, Scopus and Google Scholar

- Research which is freely available for redistribution

Submit your manuscript at www.biomedcentral.com/submit
C) Biomed Central 